\title{
Developmental Outcome in Children with Malnutrition
}

\author{
Chattopadhyay $\mathbf{N}^{1}$, Saumitra $\mathbf{M}^{2}$
}

${ }^{1}$ Dr. Nandita Chattopadhyay, DCH, DNB (Ped), Professor of Pediatrics, ${ }^{2} \mathrm{Dr}$. Masani Saumitra, DCH, MD (Ped), Assistant Professor of Pediatrics. Both from the IQ City Medical College, Durgapur, West Bengal.

\section{Address for correspondence:}

Dr. Nandita Chattopadhyay

22M Srinath Mukherjee Lane

Kolkata 700030 , India.

Tel: +919830005780

E-mail: chattnan@gmail.com

\section{How to cite}

Chattopadhyay N, Saumitra M. Developmental Outcome in Children with Malnutrition. J Nepal Paediatr Soc 2016;36(2):170-177.

doi: http://dx.doi.org/10.3126/jnps.v36i2.14619

This work is licensed under a Creative Commons Attribution 3.0 License.

\section{(c) (i)}

\begin{abstract}
Background: Developmental challenges and malnutrition are two major childhood health problems in the developing world and malnutrition is a major risk factor for poor development, which can, ultimately, lead to developmental challenges with life-long implications, affecting the individual, the family and the society at-large.Materials and Methods: We searched PUBMED \& COCHRANE REVIEW databases, published documents from WHO, UNICEF, UNDP and the World Bank and citations thereof, for relevant literature on brain development and malnutrition, dietary supplementation and brain development. Results: Effect of nutrition on the developing brain has been thoroughly studied and established. Undernutrition, particularly during fetal and $1^{\text {st }}$ two years of postnatal life, is a major risk factor for poor neuro-development, leading to motor, cognitive and speech delay, as well as behavioral problems and learning disabilities. Macro and micro-nutrients, like proteins, Iron, lodine, Zinc, vitamins-B, $C$ and $D$, choline and essential fatty acids are essential for proper brain development. Supplementation of pregnant and lactating mothers, infants and toddlers with multiple micronutrient, specially Iron, lodine, Vitamins B12 and Folate and choline has been found beneficial, particularly among the vulnerable population.Conclusion: Dietary supplementation for pregnant and lactating mothers, infants and toddlers along with a congenial socio-emotional environment and cognitive stimulation from an early age can go a long way to help the child at-risk attain his developmental potential.
\end{abstract}

Key words: Brain development, under-nutrition, supplementation

\section{Introduction}

$\mathrm{M}$ alnutrition and developmental challenges are both major health problems of childhood, particularly affecting the developing world. Over 1 billion people worldwide are under-nourished and 1 billion live with disability ${ }^{1,2}$. According to the UNICEF-WHO- World Bank Joint Child Malnutrition Estimates of $2014^{3}$, globally 165 million children under 5 are stunted, 101 million are underweight and 52 million have wasting. $71 \%$ of the severely wasted, $56 \%$ of the stunted 
and $67 \%$ of the underweight children hail from Asia. The prevalence of child under-nutrition in India is among the highest in the world; nearly double that of sub-Saharan Africa. Although levels of under-nutrition in India declined modestly during the 1990s, the reductions lagged far behind that achieved by other countries with similar economic growth rates ${ }^{4}$

Various factors like under-nutrition, poor stimulation and social interaction, environmental toxins, infections and stress during foetal life and early years of postnatal life can affect the structure and function of the brain with long-lasting effect on motor, cognitive and emotional development. Aberrations in neurodevelopment may lead to various conditions ranging from cerebral palsy to poor cognition and global developmental delay (GDD), language and communication disorders, behavioral problems like ADHD (Attention Deficit Hyperactivity Disorder), autism spectrum disorder (ASD), learning disabilities and dyslexia.

The International Child Development Steering group presented an estimate in $2007^{5}$ that more than 200 million children under 5 , mostly from Sub-Saharan Africa and South Asia, do not attain their developmental potential. $80 \%$ of world's disabled population lives in low income countries ${ }^{6}$. A recent survey of disability in 18 low and middle income countries showed that $23 \%$ of 2-9 year old children had or were at risk for disabilities ${ }^{7}$. Developmental delays in early childhood are estimated to affect about $10 \%$ of children in India ${ }^{8}$.

Studies from across the globe indicate that malnutrition is closely linked with developmental delay in all domains. In this review we propose to look into how and to what extent malnutrition and development are inter-dependent and how different risk factors come into play in causing both malnutrition and poor development.

\section{Methods}

For this purpose we searched databases like PUBMED \& COCHRANE REVIEW and published documents from WHO, UNICEF, UNDP and the World Bank for relevant literature, using ' undernutrition AND brain development' and 'dietary supplementation AND brain development' as search words. Relevant citations from retrieved articles were also included. Restricted to studies from 1995 onwards, published in English and done on human population, a total of 761 articles were retrieved, of which 97 were selected as relevant, which included 20 review articles, 6 global reports, and 61 clinical trials.

\section{Discussion}

\section{Nutrition \& Brain Development}

A brief account of the role of nutrients in brain development, will explain, physiologically, how malnutrition can be a risk factor for neuro-development. Brain development starts from the $22^{\text {nd }}$ day of conception with the in folding of the neural plate and continues rapidly-through-out gestation and the first two years of life, with neurogenesis, axonal and dendritic growth, synaptogenesis, programmed cell death and pruning, myelination and gliogenesis ${ }^{9}$ and various macro and micro-nutrients play their role at the different stages of development.

The developing brain between 24-42 weeks of gestation is particularly vulnerable to nutritional insults. Human studies reveal that maternal malnutrition can result in global and specific neurodevelopmental sequelae developing at different stages of life. Hippocampus, cortex and auditory area are most vulnerable to nutritional deprivation in early pregnancy ${ }^{10}$ which may lead to poor cognition, motor and speech delay. Effects may also be evident later in life in the form of ADHD and conduct disorders ${ }^{11,12}$. Walther FJ had demonstrated in his study that both verbal comprehension and expressive language were significantly less developed in IUGR babies and a firm relation existed between language delay and behavioral problems ${ }^{13}$.The brain's vulnerability at this stage may outweigh its plasticity resulting in brain dysfunction even after post-natal repletion ${ }^{14}$.

Different nutrients prefentially affect different brain functions, for example, protein-energy malnutrition causes global deficits, and Iron deficiency alters myelination, monoamine neurotransmitter synthesis, and hippocampal energy metabolism in the neonatal period, affecting motor development, cognition and memory. Zinc deficiency alters autonomic nervous system regulation and hippocampal and cerebellar development. Long-chain polyunsaturated fatty acids are important for synaptogenesis, membrane function, and, potentially, myelination. The impact of nutrients on permanent cognitive deficits is influenced by various factors like a) degree of deficiency, b) timing of deficiency, c) environmental stimulation, d) poverty, e) poor health care, f) maternal education etc ${ }^{15}$.

\section{Clinical Correlation}

The co-existence of malnutrition and developmental delay has been studied in various geographic and socio- 
economic fields and growth retardation in the form of stunting, as a result of poor nutrition has been identified as a major indicator of poor development ${ }^{5}$.

Studies have shown that children exposed to severe acute malnutrition in early life have poor cognitive function, poor school achievement and behavioral problems ${ }^{16,17,18,19,20,21}$, and may also progress to attention deficit and lower socio-economic status in adulthood ${ }^{22}$. Chronic malnutrition in the form of underweight or stunting in children below two years can lead to deficits in cognition and scholastic achievement in later childhood and adolescence.

Longitudinal studies conducted in Pakistan, Guatemala, Peru, Philippines and Jamaica ${ }^{23,24,25,26}$ have shown a relation with age of walking, cognition, IQ and school enrolment and dropout. In a meta-analysis in 2007, Walker SP, etal ${ }^{27}$ demonstrated that moderate to severe stunting was associated to the scores on cognition and the effect size varied from 0.4-1.05 SD. Low weight-for-age and height-for-age were also reported to be associated with developmental delay from studies conducted in India, Ethiopia and Bangladesh 28,29,30. Similar associations were also reported from Papua, New Guinea, Guatemala, Chile, Jamaica and Kenya.So we may conclude that clinical assessment also reveals that malnutrition has a definite relation to poor development, both motor and cognitive.

Poor nutrition also affects the temperament and behavior of children. In studies from Jamaica and Bangladesh, stunted children were found to be less happy and enthusiastic, showing more apathy and were less sociable than well-nourished controls, but the long-term effect on behavior have been shown to be reversible ${ }^{31}$.

Developmental challenges may, in its turn, perpetuate the malnourished state. The challenged child cannot compete for the family plate in a setting where food quantum is restricted, which leads to less food intake. These children tend to be neglected in the family. Moreover, recurrent infections, chronic diseases and vomiting in these vulnerable children further affect their nutrition ${ }^{6}$.

Correlation between malnutrition and poor development has been studied extensively in international adopted children (IAC). IAC commonly show features of growth retardation and developmental delays ${ }^{32,33,34}$, which possibly is a result of the psychosocial deprivation, poor nutrition and infections. A multi-country meta-analysis and a large Rumanian study have shown that height \& weight show greater catch up than head circumference ${ }^{35,36}$ and a few studies have shown good catch up in developmental milestones too ${ }^{34,36,37}$, though long term deficits in the form of Specific Learning Disability and poor executive function tend to persist ${ }^{38}$. One cross sectional study has shown that lower $Z$ scores for height, weight and head circumference were associated with higher incidence of delayed motor and language skills. A longitudinal study from Cleveland, Ohio followed 58 IAC below 42 mo of age, for a period of one year, to demonstrate that nutritional status had a significant impact on cognitive and psychomotor development, at the time of adoption as well as throughout the catch up period ${ }^{38}$.

\section{Common Risk Factors}

Compromised development in the first 5 years of life and poor nutrition are commonly linked to various other biological and social factors. The International Child Development Steering Group led by Susan P Walker in $2007^{39}$ identified modifiable risk factors like inadequate cognitive stimulation, iodine deficiency and iron deficiency anaemia. The same authors, in 2011, have emphasised on other risk factors like Malaria, IUGR, violence and exposure to heavy metals, maternal depression, institutionalization and societal violence, with adequate research evidence ${ }^{7}$ as contributing factors.

Poor nutrition in mother can lead to IUGR and poor brain development. LBW babies showed delayed development at 1 year of age in a study from Brazil ${ }^{40}$. Though association between birth size and development at 6 and 24 months has been demonstrated, evidence of long-term effects on neuro-development are less consisitent ${ }^{7}$. Protective factors after birth, as discussed below, may reduce the risk of long term effects. Preterm babies are also vulnerable to the effects of malnutrition, largely affecting later cognitive development ${ }^{41,42}$ and improving early energy deficit in them may promote brain growth ${ }^{43}$

Mothers with nutritional deficiencies are more prone to infections including malaria, which in turn, can impede fetal development and lead to IUGR. A malnourished short statured mother is likely to have cephalo-pelvic disproportion, leading to birth trauma and birth asphyxia, which may also lead to brain damage in the newborn.

Protective factors have also been identified which attenuate the negative effects of risk factors. These factors need active promotion to curb developmental 
impairment in children. Major protective factors are breast feeding, maternal education and socio-emotional stimulation ${ }^{7}$.

Breast feeding has been proved to have a definite impact on cognitive and emotional development of the child, both through the nutritional value of breast milk and better emotional bonding between mother and infant. Several studies performed worldwide have demonstrated strong correlation between duration of exclusive breast feeding and an improved developmental score in all age groups and at all geographical locations. Duration of exclusive breastfeeding also has a significant impact on cognitive development ${ }^{44}$. A study on 771 low birth weight babies revealed that breast fed babies had a 8 point advantage in the Bayley mental developmental indexover infants who were denied breast feeding. The results of a large, cluster-randomized trial of a breastfeeding promotion intervention in the Republic of Belarus have also yielded important positive findings bearing on the long-term health and neuro-developmental outcome ${ }^{45}$. Results from a Brazilian study suggest that the impact of breastfeeding on intellectual development may lead to sizeable differences in adult education and wageearning performance ${ }^{46}$.

Maternal education is directly linked with better ante-natal care, smaller family size and better nutrition and healthcare for the children. Young children of educated mothers have higher levels of cognitive development ${ }^{47}$. Even high-risk infants show better developmental trajectories when born to educated mothers ${ }^{48}$. EL Prado, in his study made an interesting observation that an improvement in maternal cognition with multi micro-nutrient (MMN) supplementation increased the quality of care mothers provide for their infants, thus enhancing neuro-development. This is an indirect impact of maternal nutrition on infant health ${ }^{49}$.

\section{Supplementation}

Trials on food supplementation provide stronger evidence of cause and effect relation between nutrition and brain development. As nutritional deficiency has major impact on brain development in the fetal life and $1^{\text {st }}$ two years of post-natal life, all supplementation should be aimed during this period. It has been shown that the adverse effects of early malnutrition on cognitive functioning appear to diminish over time ${ }^{50}$ possibly due to the neuro-plasticity of the brain. Nutrient supplementation and psycho-social stimulation helps in overcoming the damage. Stunted children who had experienced catchup growth had verbal vocabulary and quantitative test scores that did not differ from children who were not stunted $^{51}$. Supplementation in older children does not demonstrate such an impact on cognition. A review of 13 randomized controlled trials published since 2000 , found a lack of consistency in the impact of micronutrient supplementation in older children aged 5-15 years, on intelligence, long term mental functions and school examination grades of the children. A beneficial effect of micronutrient supplementation on short term memory was more consistently reported ${ }^{52}$.

Iron deficiency anaemia in infancy affects motor and cognitive development while IDA in children results in poor cognition and school achievement ${ }^{53,54}$. Long term effects may persist even with provision of treatment in infancy ${ }^{55}$. Adequate maternal Iron intake and provision of Iron to infants in low \& middle income countries have led to improved outcomes ${ }^{56,57}$. A Costa Rican study in $2006^{54}$ showed that children with chronic IDA did not catch up in cognitive development with the control group and the gap in IQ levels increased with age, which was more pronounced among children from low income families.

Studies have shown iodine deficiency to affect IQ by upto $12.5-13.5$ points $^{58}$. Prevention of lodine deficiency in pregnant mothers can help promote neurodevelopment in children.

Essential Fatty acids (EFA) are important for neurogenesis and myelinisation, but the benefits of EFA supplementation is not yet well established. Use of EFA containing formula in term babies showed no effect on neuro development ${ }^{59,60}$, whereas beneficial effect has been seen in pre term babies. EFA supplementation in children in low \& middle income countries shows mixed results: studies from Turkey, Ghana \& China ${ }^{60,61}$ suggest positive impact whereas trials in Gambia and Malwai, India ${ }^{60,62,63}$ showed no effect. The effect of prenatal EFA supplementation on fetal brain development is also not clear.

Zinc contributes to brain structure through its role in DNA and RNA synthesis ${ }^{64}$. However, randomized trials in Nepal and Peru ${ }^{57,65}$ have shown no effect of Zinc supplementation in pregnancy on neuro-development. Most trials on $\mathrm{Zn}$ supplementation in infancy showed improvement only in motor development ${ }^{9}$.

Thiamine deficiency with neurological symptoms and poor language development is relatively high in low income countries ${ }^{66}$.Other observational studies have demonstrated association between infant development and maternal niacin and B6 intake and infant cobalamine 
and folate status ${ }^{67}$. Molloy AM etal have established that serum concentration of Vitamin B12 ( $<250 \mathrm{ng} / \mathrm{l})$ during pregnancy has high correlation with neural tube defect in foetus ${ }^{68}$ and significant association with cognitive performance ${ }^{69}$ Another Indian study adds that higher maternal folate levels predict better cognitive development in the child $^{70}$. Vitamin $\mathrm{C}$ is a pivotal antioxidant in the brain and neonatal brain is particularly susceptible to vitamin C deficiency and may adversely affect early brain development ${ }^{71}$. The fetus and neonate have high demands for choline, while, pregnancy and lactation are periods when maternal reserves of choline are depleted, hence maternal dietary intake/ supplementation is particularly important for normal brain development of the offspring, especially memory performance ${ }^{72}$. Vitamin D plays an important role in brain functioning, but the impact of maternal vitamin $D$ deficiency on the neuro-cognitive development of the offspring remains equivocal ${ }^{73,74}$.

The present consensus is that the effect of supplementation is more pronounced in the vulnerable groups, such as mothers with a poor nutritional level and very low birth weight or preterm babies. A review conducted by Morse NL of studies from 2000 to 2012 revealed that maternal DHA intake during pregnancy and/or lactation can prolong high risk pregnancies, increase birth weight, head circumference and birth length, and can enhance visual acuity, hand and eye coordination, attention, problem solving and information processing. Vitamin $\mathrm{D}$ helps maintain pregnancy and promotes normal skeletal and brain development. Folic acid is necessary for normal foetal spine, brain and skull development. lodine is essential for thyroid hormone production necessary for normal brain and nervous system development during gestation that impacts childhood function, thus concluding that maternal supplementation within recommended safe intakes in populations with dietary deficiencies may prevent many brain and central nervous system malfunctions and even enhance brain development and function in their offspring $^{75}$

Moreover, difference in neuro-development with supplementation though not remarkable in the toddler age group, assessment at an older age has revealed better cognition, memory, and behavioral maturation like rule learning and inhibition ${ }^{76}$. Hence dietary supplementation may be considered beneficial in the long run.

Newer aspects of the role of nutrients in brain development is also being explored. A recent study suggests that nutritional components with immunomodulatory and/or anti-inflammatory effects may serve as neuroprotective agents by preventing Inflammation and perinatal infection of the neonatal brain, which plays a crucial role in the pathogenesis of white matter injury, To quote a study by Keunek $\mathrm{K}$ "Growing evidence supports the existence of a microbiome-gut-brain axis. The microbiome is thought to interact with the brain through immunological, endocrine, and neural pathways. Consequently, nutritional components that may influence gut microbiota may also exert beneficial effects on the developing brain. Based on these properties, probiotics, prebiotic oligosaccharides, and certain amino acids are potential candidates for neuroprotection"77. It is thus evident that various nutrients play their roles in brain development and a balanced diet with multi-nutrient supplementation is more important than individual supplementations for normal brain development. Trials that provide supplement to both pregnant mothers and children up to age two years demonstrated stronger evidence of long term positive effect.

\section{Conclusion}

Developmental challenges account for major morbidity and disability in childhood as well as compromised output in adult life. Children with poor cognitive levels suffer in education and ultimately earn less as adults, leading to further poverty. Moreover, poor cognitive development and lack of education in women is related to increased fertility, poor child survival and inadequate environmental stimulation for the offsprings, thus perpetuating the cycle of under-nutrition, poor development and poverty.

\section{Recommendations}

Provision of proper nutrition along with a congenial socio-emotional environment and cognitive stimulation from an early age will help the child to attain his developmental potential. Dietary supplementation for pregnant and lactating mothers, infants and toddlers with Iron, lodine, Vitamins B12 and Folate and choline can go a long way to augment the child's neuro-development. $A$ balanced diet and a stimulating environment provided at home and through educational programs will be conducive to development for the children at risk.

\section{Key Messages}

- Malnutrition hinders motor, cognitive and behavioral development in a child 
- The most vulnerable age for impairment of brain development is the fetal life and $1^{\text {st }} 2$ years of postnatal life

- Dietary supplementation in pregnant and lactating mothers and children upto 2 years, particularly among the under privileged can help improve neuro-development in children.

\section{References}

1. FAO, WFP, IFAD: The State of Food Insecurity in the World 2014. Rome, FAO, 2014

2. WHO and World Bank: World Report on Disability, 2011. Available at: http://whqlibdoc.who.int/ publications/2011/9789240685215_eng.pdf.

3. UNICEF-WHO-World Bank Joint child malnutrition estimates, 2012 : website http://www.who.int/ nutgrowthdb/estimates2012/en/ (last accessed 27.02.2015)

4. Gragnolati M, Shekar M, Gupta MD, Bredenkamp C, Lee YK. India's Undernourished Children: A Call for Reform and Action. Available from: http://hetv.org/ india/mh/nutrition/IndiaUndernourishedChildrenFinal. pdf [accessed last on 02.03.15]

5. Kerac M,Postels DG,Mallewa M,Jalloh AA, Voskuijl WP et al. The Interaction of Malnutrition and Neurologic Disability inAfrica. SeminPediatrNeurol2014;21:42-49.

6. Operational Guidelines, RashtriyaBalSuraksha Karyakram (RBSK), under NRHM, Govt of India. Website: http://nrhm.gov.in/nrhm-components/ rmnch-a/child-health-immunization/rashtriyabal-swasthya-karyakram-rbsk/background.html [ACCESSED on 05.03.15]

7. Elizabeth L Prado and Kathryn G Dewey. Nutrition and brain development in early life. Nutr Rev 2014;72(4):267-84

8. Walker SP, Wachs TD, Grantham-McGregor S, Black MM, Charles A, Nelson CA et al. Inequality in early childhood: risk and protective factors for early child development. Lancet2011;378:1325-38

9. Grantham-McGregorS,CheungYB,CuetoS, Glewwe P, Richter L, Strupp B etal. Developmental potential in the first 5years for children in developing countries. Lancet2007;369;60-70.

10. Penindo $A B$, Rezindo GH, Abreu RV. Malnutrition during central nervous system growth and development impairs permanently the subcortical auditory pathway. NutrNeurosci 2012;15:31-36.

11. GallerJR,BryceCP,WaberDP,etal. Infant malnutrition predicts conduct problems in adolescents. NutritionalNeurosci2012;15;186-92.

12. Galler JR,BryceCP,ZichlinML. Infant malnutrition is associated with persisting attention deficits in middle adulthood. JNutr 2012;142:788-94.
- Multi-nutrient supplementation is much more effective than single nutrient therapy.

- A balanced and complete diet along-with early psycho-social stimulation promotes brain development.

13. Walther FJ, Ramaekers LH. Language Development at the age of 3 years of infants malnourished in utero. Neuropediatrics 1982;13(2):77-81.

14. Georgieff MK. Nutrition and the developing brain:Nutrient priorities measurement. AmJClinNutr2007;85:614S-620S.

15. Prado EL1, Dewey KG, Nutrition and brain development in early life. Nutr Rev 2014;72(4):26784.

16. Grantham-McGregor S. A review of studies of the effect of severe malnutrition on mental development. J Nutr 1995;125(Suppl 8):2233S-2238S

17. Beasley NMR, Hall A, Tomkins AM.The health of enrolled and non enrolled children of school age in Tanga, Tanzania. Acta Trop 2000;76:223-29.

18. Hutchinson SE, Powell CA, Walker SP, Chang SM, Grantham-McGregor SM. Nutrition, anaemia, geohelminth infection and school achievement in rural Jamaican primary school children. Eur J ClinNutr 1997;51:729-35.

19. Agarwal, DK, Upadhyay SK, Tripathi AM, Agarwal KN. Nutritional status, physical work capacity and mental function in school children. Nutritional Foundation of India, 1987.Scientific Report No. 6.

20. Shariff ZM, Bond JT, Johnson NE. Nutrition and educational achievement of urban primary schoolchildren in Malaysia. Asia Pacifi c J ClinNutr 2000;9:264-73.

21. Partnership for Child Development. An association between chronic undernutrtition and educational test scores in Vietnamese children. Eur J ClinNutr 2001;55:801-04

22. Galler JR, Bryce C,Waber DP. Socioeconomic outcomes in adults malnourished in the first year of life: a 40-year study. Pediatrics 2012;130:e1-e7

23. Cheung YB, Yip PSF, Karlberg JPE. Fetal growth, early postnatal growth and motor development in Pakistani infants. Int J Epidemiol 2001;30 66-72

24. Kuklina EV, Ramakrishnan U, Stein AD, Barnhart $H H$, Martorell R. Growth and diet quality are associated with the attainment of walking in rural Guatemalan infants. J Nutr 2004;134:3296-300.

25. Berkman DS, Lescano AG, Gilman RH, Lopez SL, Black MM. Effects of stunting, diarrhoeal disease, and parasitic infection during infancy on cognition in late 
childhood: a follow-up study. Lancet 2002;359:56471.

26. Martorell R, Rivera J, Kaplowitz J, Pollitt E. Long term consequences of growth retardation during early childhood. In: Hernandez M, Argenta J, eds. Human growth: basic and clinical aspects. Amsterdam: Elsevier, 1992: 143-149.

27. Walker SP, Chang SM, Powell CA, SimonoffE, Grantham-McGregor SM. Early childhood stunting is associated with poor psychological functioning in late adolescence and effects are reduced by psychosocial stimulation. J Nutr. 2007;137(11):2464-69

28. Vazir S, Naidu AN, Vidyasagar P. Nutritional status, psychosocial development and the home environment of Indian rural children. Indian Pediatr 1998;35:95966.

29. Hamadani JD, Fuchs GJ, Osendarp SJ, Khatun F, Huda SN, Grantham-McGregor SM. Randomized controlled trial of the effect of zinc supplementation on the mental development of Bangladeshi infants. $A m ~ J$ ClinNutr 2001;74:381-86.

30. Hamadani JD, Fuchs GJ, Osendarp SJ, Huda SN, Grantham-McGregor SM. Zinc supplementation during pregnancy and effects on mental development and behaviour of infants: a follow up study. Lancet 2002;360:290-94.

31. Liu J1, Raine A. The effect of childhood malnutrition on externalizing behavior CurrOpinPediatr2006;18(5):565-70

32. Albers LH, Johnson DE, Hostetter MK, Iverson S, Miller LC. Health of children adopted from the former Soviet Union and Eastern Europe. Comparison with preadoptive medical records. JAMA 1997;278:922924.

33. Johnson DE, Miller LC, Iverson S, Thomas W, Franchino B, Dole K, Kiernan MT, Georgieff MK, Hostetter MK. The health of children adopted from Romania. JAMA1992;268:3446-451.

34. Lien NM, Meyer KK, Winick M. Early malnutrition and "late" adoption: A study of their effects on the development of Korean orphans adopted into American families. Am J ClinNutr 1977;30:1734-39.

35. Van ljzendoorn $\mathrm{MH}$, Bakermans-Kranenburg $\mathrm{MJ}$, Juffer F. Plasticity of growth in height, weight, and head circumference: Meta-analytic evidence of massive catch-up after international adoption. $J$ Dev. BehavPediatr 2007;28:334-43.

36. Rutter M. Developmental catch-up, and deficit, following adoption after severe global early privation. English and Romanian Adoptees (ERA) Study Team. J Child PsycholPsychiatr 1998;39:465-76.

37. Benoit TC, Jocelyn LJ, Moddemann DM, EmbreeJE. Romanianadoption.The Manitoba experience. ArchPediatrAdolesc Med 1996;150:1278-82.
38. Park H, Bothe D, Holsinger E, Kirchner HL, Olness $\mathrm{K}$, Mandalakas A. The Impact of Nutritional Status and Longitudinal Recovery of Motor and Cognitive Milestones in Internationally Adopted Children. Int J Environ Res Public Health 2011;8(1):105-116.

39. Walker SP, Wachs TD, Meeks-Gardner JM,Lozoff B, Wasserman GA, Pollitt E, et al. Child development: risk factors for adverse outcomes in developing countries. Lancet 2007;369:145-57

40. Grantham-McGregor SM, Lira PI, Ashworth A, Morris SS,Assuncao AM. The development of low birth weight term infantsand the effects of the environment in northeast Brazil. J Pediatr1998;132:661-66.

41. Lundgren EM, Tuvemo T. Effects of being born small for gestational age on long-term intellectual performance. Best Pract Res ClinEndocrinolMetab2008;22:477-88.

42. Embleton ND. Early nutrition and later outcomes in preterm infants. World Rev Nutr Diet 2013;106:26-32.

43. Tan M1, Abernethy L, Cooke R. Improving head growth in preterm infants--a randomised controlled trial II: MRI and developmental outcomes in the first year. Arch Dis Child Fetal (Neonatal Ed) 2008;93(5):F3426.

44. Rao MR, Hediger ML, Levine RJ, Naficy AB, Vik T. Effect of breastfeeding on cognitive development of infants born small for gestational age. ActaPaediatr2002;91:267-74

45. Kramer MS, Aboud F,Mironova E,Vanilovich I, Platt RW, MatushL et al. Breastfeeding and child cognitive development: new evidence from a large randomized trial. Arch Gen Psychiatr 2008;65:578-84.

46. Victora CG, Barros FC, Horta BL, et al. Breastfeeding and school achievement in Brazilian adolescents. ActaPaediatr 2005;94:1656-60.

47. Barros AJ, Matijasevich A, Santos IS, Halpern R. Child development in a birth cohort: effect of child stimulation is stronger in less educated mothers. Int $\mathrm{J}$ Epidemio/2010;39: 285-94.

48. Wang LW, Wang ST, Huang CC. Preterm infants of educated mothers have better outcome. ActaPaediatr 2008;97:568-73.

49. Prado $\mathrm{EL}^{1}$, Ullman $\mathrm{MT}$, Muadz $\mathrm{H}$, Alcock KJ, Shankar $\mathrm{AH}$. The effect of maternal multiple micronutrient supplementation on cognition and mood during pregnancy and postpartum in Indonesia: a randomized trial.SUMMIT Study GroupPLOS One 2012;7(3):e32519.

50. Boddy J1, Skuse D, Andrews B. The developmental sequelae of nonorganic failure to thrive. J Child PsycholPsychiatr 2000;41(8):1003-14

51. Martins VJ, Toledo Florêncio TM, Grillo LP, do Carmo PFM, Martins PA, Clemente AP et al. Long-lasting effects of undernutrition. Int J Environ Res Public Health $2011 ; 8(6): 1817-46$. 
52. Khor GL, Misra S. Micronutrient interventions on cognitive performance of children aged 5-15 years in developing countries. Asia Pac J ClinNutr 2012;21(4):476-86.

53. Lozoff B, Klein NK, Nelson EC. Behavior of infants with iron-deficiencyanemia. Child Dev 1998;69:25-36.

54. Lozoff B, Jimenez E, Smith JB. Double burden of iron deficiency in infancy and lowsocioeconomic status: a longitudinal analysis of cognitive test scores to age 19 years. Arch PediatrAdolesc Med 2006;160:1108-113.

55. Rao R, Tkac I, Schmidt AT, Georgieff MK. Fetal and neonatal iron deficiency causes volume loss and alters the neurochemical profile of the adult rat hippocampus. NutrNeurosci. 2011;14:59-65.

56. Walker SP, Wachs TD, Meeks-Gardner JM, et al. Child development: risk factors for adverse outcomes in developing countries. Lancet 2007;369:145-57.

57. Christian P, Murray-Kolb LE, Khatry SK, et al. Prenatal micronutrient supplementation and intellectual and motor function in early school-aged children in Nepal. JAMA 2010;304:2716-723.

58. Qian M, Wang D, Watkins WE, Gebski V, Yan YQ, Li Met al. The effects of iodine on intelligence in children: a meta-analysis of studies conducted in China. AsiaPac J ClinNutr2005;14:32-42.

59. Makrides M, Collins CT, Gibson RA. Impact of fatty acid status on growth and neurobehavioural development in humans. Matern Child Nutr 2011;7(Suppl 2):80-88.

60. Unay B, Sarici SU, Ulas UH, kin R, Alpay F, Gokcay E. Nutritional effects on auditory brainstem maturation in healthy term infants. Arch Dis Child Fetal Neonatal Ed 2004; 89:F177-F179.

61. Adu-Afarwuah S, Lartey A, Brown KH,Zlotkin S, Briend A, Dewey KG. Randomized comparison of 3 types of micronutrient supplements for home fortification of complementary foods in Ghana: effects on growth and motor development. Am J ClinNutr 2007;86:412-20.

62. van der Merwe LF, Moore SE, Fulford AJ, Halliday KE, Drammeh S, Young Set al. Long-chain PUFA supplementation in rural African infants: a randomized controlled trial of effects on gut integrity, growth, and cognitive development. Am J ClinNutr 2013;97:45-57.

63. Phuka JC, Gladstone M, Maleta K, Thakwalakwa C, Cheung YB, Briend A. Developmental outcomes among 18-month-old Malawians after a year of complementary feeding with lipidbased nutrient supplements or corn-soy flour. Matern Child Nutr 2012;8:239-48.

64. Sandstead $\mathrm{HH}$, Frederickson CJ, Penland JG. History of zinc as related to brain function. J Nutr 2000;130(Suppl 2):496S-502S.

65. Caulfield LE, Putnick DL, ZavaletaN,Lazarte F, Albornoz C, Chen P, et al.Maternal gestational zinc supplementation does not influence multiple aspects of child development at 54 mo of age in Peru. Am J ClinNutr 2010;92:130-36.

66. Fattal-Valevski A1, Azouri-Fattal I, Delayed language development due to infantile thiamine deficiency. Dev Med Child Neurol 2009;51(8):629-34

67. Kirksey A, Wachs TD, Yunis F, Srinath U. Relation of maternal zinc nutriture to pregnancy outcome and infant development in an Egyptian village. Am J ClinNutr 1994;60:782-92.

68. Molloy AM, Kirke PN, Troendle JF, Burke H, Sutton M, Brody LCet al. Maternal vitamin B12 status and risk of neural tube defects in a population with high neural tube defect prevalence and no folic acid fortification. Pediatrics 2009;123:917-23.

69. Strand TA1, Taneja S, Ueland,Cobalamin and folate status predicts mental development scores in North Indian children 12-18 mo of age. Am J ClinNutr. 2013;97(2):310-17.

70. Veena SR1, Krishnaveni GV, SrinivasanK . Higher maternal plasma folate but not vitamin B-12 concentrations during pregnancy are associated with better cognitive function scores in 9- to 10- year-old children in South India. J Nutr2010;140(5):1014-22.

71. Tveden-Nyborg P, Lykkesfeldt J. Does vitamin C deficiency result in impaired brain development in infants? Redox Rep 2009;14(1):2-6

72. Blusztajn JK, Mellott TJ, Choline nutrition programs brain development via DNA and histone methylation. Cent NervSyst Agents Med Chem 2012;12(2):82-94

73. Hart PH, Lucas RM. Vitamin D in fetal development: findings from a birth cohort study. Pediatrics 2015;135(1):e167-73.

74. Strøm M, Halldorsson T, Hansen S, Granström C. Vitamin $D$ measured in maternal serum and offspring neurodevelopmental outcomes: a prospective study with long-term follow-up. Ann NutrMetab 2014;64(34):254-61.

75. Morse NL. Benefits of docosahexaenoic acid, folic acid, vitamin $D$ and iodine on foetal and infant brain development and function following maternal supplementation during pregnancy and lactation. Nutrients 2012;4(7):799-840.

76. Colombo J, Carlson SE, Cheatham CL, Shaddy DJ, Kerling EH, Thodosoff JM, Gustafson KM, Brez C. Long-term effects of LCPUFA supplementation on childhood cognitive outcomes. Am J ClinNutr 2013;98(2):403-12.

77. Keunen K, van Elburg RM, van Bel F, Benders MJ. Impact of nutrition on brain development and its neuroprotective implications following preterm birth. Pediatr Res 2015;77(1-2):148-55. 